\title{
Retraction Note to: A novel approach for free vibration of circular/annular sector plates using Reddy's third order shear deformation theory
}

\author{
M. Fadaee
}

Published online: 17 May 2017

(C) Springer Science+Business Media Dordrecht 2017

\section{Retraction Note to: Meccanica (2015) 50:2325-2351 DOI 10.1007/s11012-015-0158-4}

The Editor in Chief has decided to retract this article for reasons of redundant (duplicate) publication. The article was examined following the COPE guidelines with regard to suspected redundant publication in a published manuscript. Several passages and figures in the article have been used without proper attribution and acknowledgement. The most original source papers are:

International Journal of Mechanical Sciences

Volume 79, February 2014, Pages 1-14

Accurate approach implementation in vibration analysis of thick sector plates

Mehdi Es'haghi

doi:10.1016/j.ijmecsci.2013.11.007

International Journal of Mechanical Sciences

Volume 56, Issue 1, March 2012, Pages 35-49

Benchmark solution for transverse vibration of annular Reddy plates

The online version of the original article can be found under doi:10.1007/s11012-015-0158-4.

M. Fadaee ( $\square)$

Department of Mechanical Engineering, College of Engineering, Qom University of Technology, Qom, Iran e-mail: fadaee@qut.ac.ir
H. Bisadic, M. Es'haghia, H. Roknib, M. Ilkhanic doi:10.1016/j.ijmecsci.2011.12.007

Composite Structures

Volume 92, Issue 6, May 2010, Pages 1333-1351

An exact analytical solution for freely vibrating piezoelectric coupled circular/annular thick plates using Reddy plate theory

Sh. Hosseini-Hashemia, M. Es'haghia, H. Rokni Damavandi Taherb

doi:10.1016/j.compstruct.2009.11.006

Journal of Sound and Vibration

Volume 329, Issue 16, 2 August 2010, Pages 3382-3396

Exact closed-form frequency equations for thick circular plates using a third-order shear deformation theory

Sh. Hosseini-Hashemia, M. Es'haghia, H. Rokni Damavandi Taherb, M. Fadaiea

doi:10.1016/j.jsv.2010.02.024

The author does not agree to this retraction. 